\title{
DAKWAH DAN GERAKAN ANTI ISLAM \\ (Membendung Gerakan Anti Islam Melalui Dakwah Berdimensi Kerahmatan)
}

Oleh: Muhammad Thahir

\section{IAIN Sultan Amai Gorontalo \\ Email: aqiladelina4@gmail.com}

\begin{abstract}
A new phenomenon that emerged among the fobian, where Islam is regarded as the most dangerous enemy. Phobia against Islam (Islamophobia) is a propaganda of the anti-Islam movement that was born since the WTS event in the US, where Islam is the target of suspicion as a religion that teaches violence and terrorist nests.
\end{abstract}

Keywords: Da'wah, Movement, Anti, Islam

\section{Pendahuluan}

Islam adalah agama yang mengajarkan kepada penganutnya senantiasa berserah diri dan beristiqamah (konsisten) di jalan Allah, mengikuti tuntunan Alquran dan Sunnah Rasulullah.Istiqamah dalam agama perlu sebagai bentuk konsistensi dalam menjalankan perintah-perintah Tuhan, namun tidak berarti konsistensi adalah sebuah bentuk fanatiksme agama yang berlebihan. Memang ada sebagian masyarakat muslimsecara berlebihan memahami fanatisme agama yang kemudian melahirkan kelompok-kelompok fundamentalis, radikal di mana hegemoni jihad dijadikan sebagai kekuatan dalam berbagai aksi radikal yang mereka lakukan.

Aksi-aksi teror oleh kelompok Islam radikal mengakibatkan stigma negatif muncul dari musuh-musuh Islam, bahwa Islam bukan agama kerahmatan sebagaimana yang dipahami oleh mayoritas penganutnya, Islam adalah agama teror. Begitulah salah satu alasan kelompok anti Islam yang sengaja melahirkan stigma itu untuk menyudutkan Islam. 
Sejak peristiwa runtuhnya World Trade Center (WTC) di Amerika 11 September 2011, genderang perang terhadap Islam yang dikemas dalam isu-isu teroris mulai digaungkan.Ada kecenderungan mereduksi pengertian teroris seakan identik dengan Islam. Setiap ada orang yang menyebut kata teror, maka yang ada dibenak kita adalah sosok Osama Bin Laden atau para teroris muslim lainnya. ${ }^{1}$ Dimotori oleh Amerika Serikat, propaganda gerakan anti Islamyang dikemas dalam isu terorisme bermunculan bak jamur di musim hujan. Hal ini terjadi tidak hanya di Amerika Serikat akan tetapi hingga di Eropa dan Asia, misalnya di Prancis, umat Islam diekploitasi dengan sebuah stigma dimana wanita muslim yang berhijab dan pria yang tidak berkumis menjadi obyek dan sasaran kecurigaan sebagai kelompok radikal (teroris), ${ }^{2}$ atau Geert Wilders seorang anggota parlemen di Belanda mengungkapkan kebenceiannya terhadap Islamyang melarang imigram dari negara muslim masuk ke Belanda ${ }^{3}$, atau di Australia di Kota Bendigo Victoria yang melarang pembangunan sebuah Masjid karena dituding sebagai tempat aktivitas terorisme. ${ }^{4}$

Sebuah fenomena baru yang muncul di kalangan kaum fobian, dimana Islam dianggap sebagai musuh yang paling berbahaya. Fobia terhadap Islam (Islamofobia)merupakan propaganda gerakan anti Islamyang lahir sejak peristiwa WTS di AS, dimana Islam menjadi sasaran kecurigaan sebagai agama yang mengajarkan kekerasan dan sarang teroris.

\section{Pembahasan}

\section{Dinamika Islam Kontemporer}

Islam adalah agama yang terakhir diturunkan oleh Allah Swt., kepada manusia. Islam merupakan penyempurna agama-agama sebelumnya. Islam telah menunjukkan kebenaran yang nyata dan itu terlihat dan teerkam dengan jelas

\footnotetext{
${ }^{1}$ Abdul Wahid dan Kawan-kawan, Kejahatan Terorisme Perspektif Agama, HAM, dan Hukum, Bandung; Refika Aditama, 2004.

${ }^{2}$ Lihat, http://m.republika.co.id/berita/dunia-Islam/Islam-nusantara/14/12/04ng11ng-diprancis-tidak-punya-kumis-dan-berhijab-dicurigai.

${ }^{3}$ Lihat, http://satuumat.blogspot.com/2010/07/gerakan-anti-Islam-antarabangsa.html

${ }^{4}$ Lihat, http://m.republika.co.id/berita/internasional/global/14/12/03/nfzse1-di-australiamasjid-dituding-sebagai-sarang-teroris.
} 
sepanjang perjalanan Islam. kendati demikian, kebenaran tidak selamanya dapat diterima oleh semua pihak, namu justru dimana ia berada pasti ada yang mengingkarinya. ${ }^{5}$

Kondisi seperti inilah yang terjadi terhadap Islam di mata Barat. Islam meraka anggap sebagai ancaman terbesar yang mengganggu keberlangsungan peradaban Barat. Oleh karena itu, mereka melakukan pengkajian tentang keIslaman untuk mengetahu titik lemah ajaran Islam kemudian melakukan seranganserangan dengan memutarbalikkan fakta-fakta dalam sejarah, bahkan tudingan miring kerap kali muncul menyudutkan Islam.

Dr. Haiti, seorang orientalis keturunan Libanon melancarkan tuduhan kepada Nabi Muhammad Saw., bahwa beliau adalah seorang penipu yang lihai, dimana Alquran bukan dianggap sebagai firman Tuhan melainkan buatan Muhammad sendiri. Dengan berbagai kepentingan Alquran dibuat untuk memperlancar proses adaptasi dari Mekkah ke Madinah. ${ }^{6}$

Dalam aspek kesejarahan, selanjutnya Hitti melancarkan tuduhan lain bahwa penyebaran Islam dari semenanjung Jazirah Arab ke beberapa daerah di sekitarnya termasuk hingga ke Eropa bukan atas motivasi keagamaan melainkan motivasi ekonomi, bukan atasnama Islam sebagai agama melainkan sebagai negara, bukan Muhammadanisem tetapi Arabia-nism. ${ }^{7}$ Beginilah Hitti cara memahami dan memberikan interpretasi terhadap nilai-nilai kebenaran dan faktafakta sejarah dalam Islam sebagai upaya untuk mendiskreditkan Islam sebagai alya'lu wala yu'la alaihi.

Dalam sejarah perkembangan Islam dari masa ke-masa hingga saat ini, Islam cukup banyak mendapat sorotan dan tanggapan miring oleh kalangan Barat untuk menjatuhkan dan mengkerdilkan Islam sehingga ditinggalkan oleh penganutnya. Di sejumlah wilayah di belahan bumi ini, mulai dari Amerika,

${ }^{5}$ LIhat, Devi Muharrom Sholahuddin, Islam di Mata Barat; Hegemoni Barat Terhadap Perabadan Islam, dalam http://figur-darussalam.blogspot.com./2012/06/Islam-di-mata-barathegemoni-barat.html.

${ }^{6}$ Lihat, Maryam Jamilah, Islam dan Orientalisme; Sebuah Kajian Analitik (Cet. II; Jakarta: PT. RajaGrafindo Persada, 1997). H. 13-16.

${ }^{7}$ Philip K. Hitti, Islam and The West; Kultural Survey (Princeton, N.J: D. Van Nostrand Co., Inc., 1962), h. 26-27. 
Eropa, Australia hingga ke Asia, gerakan-gerakan yang massif tetap terus dilakukan sebagai wujud ketidaksenangan serta untuk meruntuhkan Islam. Sejak peristiwa 11 September 2001, Islam menjadi bulan-bulanan bangsa Amerika dan Eropa. ${ }^{8}$ Kecurigaan terhadap Islammuncul secara berlebihan (Islamofobia), dimana Islam dianggap sebagai sesuatu yang sangat menakutkan, radikal, tukang teror, bom bunuh diri bahkan pembunuh berdarah dingin. Sehingga oleh beberapa negara di Eropamengeksploitasi umat Islam dengan berbagai bentuk kebijakan untuk mencegah penyebaran Islam di negara mereka. Misalnya di Perancis Islam perempuan dilarang berhijab, bahkan laki-laki yang berjenggot dicurigai sebagai teroris, atau di Belanda imigran muslim dilarang masuk.

\section{Bentuk-Bentuk Gerakan Anti Islam}

a. Pendangkalan ideologi

Saat ini Islam mengalami kondisi yang sangat ambigu. Di mana pengikut Islam kian hari semakin bertambah, di satu sisi. Namun pada sisi yang lain, di dalam tubuh Islamsendiri mengalami pengeroposan nilai-nilai. Pengeroposan itu terlihat dari rendahnya aplikasi keimanan atau keyakinan dalam kehidupan seharihari. Tidak terhidtung jumlah pakar dan ilmuan di bidang agama Islam, namun nilai-nilai Islam yang sesungguhnya justru jauh dari panggang dari api.

Runtuhnya nilai-nilai Islam sebenarnya tidak lepas dari lunturnya nilai kesakralan ajaran agama itu sendiri. Akibat rasionalitas ${ }^{9}$ yang dijadikan tumpuan di dalam mempelajari dan memahami agama menjadikan agama ini bak sebuah musium

\footnotetext{
${ }^{8}$ Tragedi 11 September merupakan tragedy kemanusiaan yang sangat mengerikan dimana Osama Bin Laden bersana pengikutnya dianggap sebagai pelaku teror tersebut. Meskipun tidak diragukan lagi bahwa ada banyak bukti-bukti tak langsung untuk mengaitkan Osama dengan pembunuhan itu, pemerintah Amerika Serikat belum memberikan bukti konsklusif yang tak terbantahkan tentang keterlibatannya. Lihat, Chandra Musaffar, Muslim Dialog dan Teror (Cet. I; Jakarta: PT. Ekuator Publika, 2004), h.173., atau Lihat Prancis Boyle, Special Introduction, The Criminality of Nuclear Deterence, (Atlanta: Clarity Press, 2002), h. 18-20.

${ }^{9}$ Salah satu implikasi rasionalitas, bahwa semua agama itu sama, membawa misi ketauhidan. Ketika para penganut agama itu benar-benar beriman kepada Tuhan-Nya, seperti Islam beriman kepada Allah dan hari kemudian maka akan mendapatkan pahalah di sisi Tuhan, (Lihar. QS. AlBaqarah:61). Dengan kata lain, sesuai firman Allah ini, terdapat jaminan teologis bagi umat beragama, apapun agamanya untuk menerima pahala (syurga) dari Tuhan. Lihat. Adian Husaini dan Nuim Hidayat, Islam Liberal, Sejarah Konsepsi, Penyimpangan dan JAwabannya (Cet. I; Jakarta: Gema Insani Press, 2002), h. 81-82.
} 
besar yang hanya sekedar diketahui tetapi tidak digunakan dalam kehidupan sehari-hari. Agama hanya dipelajari untuk mengetahui adanya Tuhan atau sejarah ajaran-ajaran Muhammad dan nabi-nabi lain. Pengetahuan agama tidak diaplikasikan dalam kehidupan sehari-hari. Tuhan hanya dianggap objek pemahaman dan bukan untuk ditakuti, karena ajaran-ajaran yang terdapat di dalam Alquran dianggap sebagai pengetahuan belaka. ${ }^{10}$

Pemahaman Islam sekedar sebagai pengetahuan berdapak pada pemahaman tidakpentingnya nilai-nilai untuk diaplikasikan dalam kehidupan sehari-hari. Itu sebabnya dalam konsep ini, ahli ilmu Islam boleh berfikir semaunya sesuai dengan rasionalitas manusia. Manusia dalam konteks ini juga dapat menegasikan perintah, larangan dan hukum-hukum Islam bahkan menegasikan Tuhan itu sendiri. Tuhan dianggap sebagai hasil imajinasi manusia yang dibuat oleh para pendahulu untuk menakut-nakuti, agar manusia tidak berbuat jahat. $^{11}$

Sebenarnya tanpa kita sadari, upaya Baratmeruntuhkan Islamsecara sistematis sudah lama dilakukan melalui pendangkalan ideologi. Hal ini diawali dengan menarik para intelektual muslim untuk belajar Islam di negara liberal tersebut dengan iming-iming berbagai fasilitas beasiswa. Melalui para intelektual muslim ini, yang telah di tanamkan ideologi-ideologi yang ingin disebarkan kepada pihak lawan. untuk belajar Islam kepada orientalis yang jelas-jelas ingin meruntuhkan Islam. secara logika memang sangat aneh, saat Barat adalah musuh besar bagi dunia Islam, tetapi para intelektualnya justru belajar Islam pada musuhnya sendiri. Para intelektual muda muslim dibiayai dan dibesarkan oleh para orientalis yang akan menggaungkan isu-isu kontroversial di dalam Islam sendiri. Dengan demikian wacana apapun yang dihembuskan oleh Baratakan mendapat legitimasi dari kaum intelektual Islam sendiri, yang kemudian akan melahirkan kekacauan antaraumat Islam. misalnya"pemberontakan" aqidah Islam oleh Ulil Absor Abdalla dengan kendaraan JIL (Jaringan Islam Liberal), atau

\footnotetext{
${ }^{10}$ Lihat, Wajiran, (Dosen Universitas Ahmad Dahlan Yogyakarta) dalam http://sosbud.kompasiana.com/2012/10/08/upaya-barat-runtuhkan-Islam-500089.html

${ }^{11}$ Lihat, Wajiran, (Dosen Universitas Ahmad Dahlan Yogyakarta) dalam http://sosbud.kompasiana.com/2012/10/08/upaya-barat-runtuhkan-Islam-500089.html
} 
Musda Mulya yang menghalalkan pernikahan sejenis ${ }^{12}$. Tokoh-tokoh yang sudah diracuni oleh pemikiran Barat inilah yang menghembuskan isu-isu rasionalisme dalam Islam sehingga melemahkan nilai-nilai kesakralan dalam Islam itu sendiri. $^{13}$

\section{Metode Kekerasan/Militer}

Amerika yang berlindung di balik jubah PBB dapat menyerang negara lain meskipun tanpa bukti atau ditentang oleh negara lain. Di Irak misalnya, berapa banyak orang muslim meninggal akibat invasi militer Amerika dengan tuduhan memiliki senjata pemusnah missal, meskipun hingga detik ini tidak bisa membuktikan tuduhannya terhadap Irak. Amerika menyerang ke Irak lebih cenderung motif untuk menguasai kekayaan alam Irak.

Begitu juga di Afganistan, saat terjadi perang dingin Soviet-Amerika, Amerika tidak berani menyerang negara itu karena memiliki peralatan super canggih, akhirnya memanfaatkan para pejuang Taliban untuk melawan Soviet, dan akhirnya bisa menang. Amerika tidak pernah menyadari berapa banyak pejuang-pejuang Taliban meninggal. Namun hanya karena Taliban ingin menerapkan syariat dalam negaranya yang didukung oleh rakyatnya sendiri, Amerika membuat skenario isu terorisme untuk menyerang balik Taliban. Bersama sekutunya Inggris, berhasil mengalahkan Taliban. ${ }^{14}$

Apa yang terjadi di Afganistan tidak jauh beda dengan di Palestina, dimana Zionis Israil melakukan pembantaian kepada anak-anak Pelestina di Gaza. Pembela HAM dunia Amerika memiliki standar ganda untuk menegakkan HAM di Israil. PBB yang seharusnya menjadi penengah dari semua kekejian ini hanya bungkam seribu bahasa terveto suara dan haknya oleh kelompok kafir Amerikan

\footnotetext{
${ }^{12}$ Lihat, http://adjis.wordpress.com/2012/12/02/konspirasi-global-menghancurkan-islamdi-indonesia/

${ }^{13}$ Lihat, Wajiran,http://www.uad.ac.id/en/infiltrasi-ideologi-barat-meruntuhkan-islam

${ }^{14}$ Lihat, https://adjhis.wordpress.com.2012/12/02/konspirasi-global-menghancurkanislam-di-indonesia/
} 
dan Zionis Israil. Seolah-olah keadilan di dunia ini hanya milik segelintir orang saja dan digunakan sekehendak mereka. ${ }^{15}$

\section{Membangun Opini Negatif}

Segala bentuk permusuhan terhadap kaum muslimin serta perlakuan diskrimitatif terhadap Islam di seluruh dunia, tidak lepas dari pemahaman bahwa Islam akan kembali menguasai dunia. Dalam menghadapi ancaman ini, Amerika Serikat menyusun strategi untuk menghancurkan Islam sejak dini sebelum menjadi kekuatan besar. Dan untuk memberikan efek global sehingga perang melawan teroris tidak lain adalah perang melawan gerakan Islam. Itulah yang kini sedang terjadi. ${ }^{16}$

Pola yang diciptakan Amerika untuk memerangi gerakan Islam ini adalah membangun opini/stigma negatif terhadap Islam yang identik dan sarang teroris. Selain itu, cara-cara yang dilakukan Amerika lainnya adalah labeling kepada seseorang atau suatu negeri. Sasaran diharapkan akan menanggapi cap tersebut tanpa memeriksa bukti. Misalnya Saddam Hussain diberi julukan "penbantai dari Bagdad", bahkan Rasulullah dijuluki "si maniak seks", atau negera yang tidak sejalan dengan Amerika di Timur tengah dicap sebagai negara militant, sementara yang sejalan dengan Amerika disebuat negara sahabat atau negara moderat. Beginilah cara Amerika mempropaganda dengan membangun stigma dengan menggunakan istilah-istilah emosional dan stereotipyng telah melekat di telinga. ${ }^{17}$

\section{Gerakan Dakwah berdimensi Ke-rahmatan lil alamin membendung Gerakan} Anti Islam

Islam sebagai agama dakwah senantiasa mendorong pemeluknya untuk aktif melakukan aktivitas dakwah. Kemajuan dan kemunduran Islam, sangat

\footnotetext{
${ }^{15}$ Lihat, https://adjhis.wordpress.com.2012/12/02/konspirasi-global-menghancurkanislam-di-indonesia/

${ }^{16}$ Lihat, http://manhajkita.blogspot.com/2012/10/upaya-as-meredam-bangkitnya-islamdi.html

${ }^{17}$ Lihat, http://ismailkarim86.wordpress.com/2009/08/19/propaganda-asing-di-balik-isuterorisme/
} 
berkaitan erat dengan kegiatan dakwah yang dilakukannya, ${ }^{18}$ baik secara personal maupun kelompok (organisasi).

Kehadiran dakwah di tengah pergolakan globalisasi modern dituntut agar ikut terlibat secara aktif di dalam memecahkan berbagai problem ${ }^{19}$ yang dihadapi umat manusia.Hal yang menjadi tantangan terbesar umat Islam sekarang ini, munculnya kelompok-kelompok terorganisir yang membenci Islam gencar melakukan propaganda, mendiskreditkan, mengaburkan ideologi Islam dan sebagai agama yang konservatif, tidak mampu mengikuti perkembangan jaman, identik dengan teroris, dan suka membunuh. Atas alasan ini, kehadiran dakwah dalam sebuah dimensi yang berbeda untuk membendung penilaian stereotip terhadap Islam yaitu dakwah berdimensi ke-rahmatan lil alamin(dakwah yang memberikan rahmat kepada seluruh manusia, sehingga ajaran Islam dapat diterima dan dapahami sebagai ajaran yang penuh dengan perdamaian). ${ }^{20}$

Orientasi dakwah berbasis rahmatan lil alamin adalah supaya Islam tidak dianggap lawan terhadap agama-agama selain Islam dan memberikan pemahaman bahwa Islam adalah agama yang mencintai perdamaian, bukan seperti yang mereka tuduhkan sebagai agama teroris namun justru sebaliknya bisa berdampingan dengan agama selain Islam.

Dakwah rahmatan lil alaminini meliputi lima aspek, yaitu, a) aspek materi dakwah yang difokuskan pada aspek kehidupan realitas sosial, b) aspek inklusivitas, c) aspek toleran terhadap agama-agama, d) aspek dakwah sebagai kritik sosial, e) aspek dakwah berwawasan perdamaian. Kelima aspek ini, sejalan dengan nilai-nilai yang terkandung dalam surat al-Kafirun: 2-6. ..."Aku tidak akan menyembah apa yang kamu sembah, dan kamu bukan penyembah Tuhan yang aku sembah, dan kamu tidak pernah (pula) menjadi penyembah Tuhan yang aku sembah, Untukmulah agamamu dan untukkulah agamaku”.

\footnotetext{
${ }^{18}$ Didin Hafidhuddin, Dakwah Aktual, (Cet. I; Jakarta: Gema Insani Press, 1998), h. 76.

${ }^{19}$ Jalauddin Rahmat, Rekayasa Sosial; Reformasi, Revolusi, atau Manusia Besar? (Cet. II; Bandung: PT. Remaja Rosada Kasya, 2000), h. 55.

${ }^{20}$ Zainuddin, dalam jurnal Dakwah UIN Sunan Kali Jaga, Dakwah Rahmatan Lil Alamin, Kajian tentang Toleransi Beragama dalam Surat al-Kafirun, Vol. X, No. 1 Januari 2009, h. 26-27.
} 
Makna yang terkandung dalam surat al-Kafirun di atas, bahwa Islam mengajarkan tentang harmonisasi antara umat beragama, menghargai tentang perbedaan agama, sikap toleran dan transparansi keyakinan. Bahkan melarang mencaci-maki terhadap orang lain yang berbeda agama. ${ }^{21}$ Olehnya itu, dakwah rahmatan lil alamin adalah dakwah yang tidak berdimensi pada doktrin atau dakwah ideologi yang fanatik, melainkan dakwah yang berdimensi ta'aruf, ukhuwah, dan ta'awun.

Apapun bentuk tuduhan dan anggapan mereka terhadap Islam, apabila nilai-nilai rahmatan lil alaminini menjadi acuan kita, maka kita tidak perlu merospon secara emosional anggapan tersebut melainkan menumbuhkan kesadaran pikiran dan keyakinan serta membagun ukhuwah yang kokoh (membangun sistem/organisasi). ${ }^{22}$

Secara strategi, langkah-langkah dakwah yang dapat dilakukan membendung serangan kelompok-kelompok anti Islam meliputi tida tahan yaitu:

1. Tahapan ideologis; upaya dalam membangun dan memantapkan fondasi kehidupan yang di atasnya akan dibangun sebuah struktur masyarakat yang kuat, dan menurut para ahli dakwah memandang tahapan pembangunan pondasi ini merupakan tahapan yang palaing penting dan menentukan dalam menjawab isu-isu pengaburan ideologi yang dilakukan oleh Amerika.

2. Tahapan Konsepsional; tahapan ini merupakan pembangunan struktur masyarakat di atas pondasi ideologis, sehingga menjadi sebuah masyarakat yang dapat mentransformasi nilai-nilai dan konsep-konsep Islam yang berlandaskan tauhid ke seluruh dimensi kehidupan. Tahapan ini merupakan upaya dakwah menepis segala bentuk konsep (tuduhan) serta serangan gerakan anti Islam, sehingga dapat dipastikan bahwa kosnep-konsep dakwah dapat sepenuhnya menwarnai kehidupan masyarakat.

${ }^{21}$ Zainuddin, dalam jurnal Dakwah UIN Sunan Kali Jaga, h. 24.

${ }^{22}$ Amrullah Achmad, "Dakwah Islam dan Perubahan Sosial Suatu Kerangka Pendekatan dan Permasalahan. Dalam Seminar Nasional dan Diskusi PLP2M, (Cet. I; Yogyakarta: Prima Duta, 1983), h. 4. Lihat Juga Didin Hafiduddin, "Manajemen Dakwah", dalam Adi Sasono (et.,al.) Solusi Islam atas Problematika Umat (Ekonomi, Pendidikan, dan Dakwah), (Cet. I; Jajarta: Gema Insani Press, 1998), h. 192-193. 
3. Tahapan Operasional; mensosialisasikan seluruh konsepsi Islam dalam alam kenyataan dan membuktikan keunggulan di hadapan konsepsi-konsepsi yang batil sehingga tidak ada lagi fitnah dan tuduhan terhadap Islam. ${ }^{23}$

Ketiga tahapan ini menjadi tahapan trategis menghadapi tantangan eksternal dakwah. Melalui argementasi-argumentasi yang kuat, dakwah harus mampu mengalahkan ideologi-ideologi domestik atau kejahiliahan bangsa Amerika dan Eropa agar tidak menjadi penghalang dalam melaksanakan dakwah.

\section{Penutup}

\section{Kesimpulan}

Pada tangga 11 September 2001, dunia digemparkan oleh sebuah peristiwa kelam dalam sejarah kehidupan manusia, yaitu runtuhnya gedung kembar kebanggaan Amerika Serikat, World Trade Center (WTC) yang mengakibatkan ribuan nyawa melayang. Osama Bin Ladeng dianggap orang yang paling bertanggung jawab atas persitiwa teror tersebut. Sehingga pemerintah Amerika Serikat mengumumkan perburuan terhadap Osama Bin Laden dengan sejumlah hadiah bagi yang bisa menemukan hidup atau mati.

Inilah awal mula genderang kebencian Amerika terhadap Islam ditabur, sejak peristiwa itu, Islam selalu dilihat sinis dan menakutkan oleh bangsa Amerika dan Eropa. Mereka dianggap sebagai kelompok-kelompok teror yang setiap saat bisa saja melakukan hal yang sama seperti Osama Bin Laden. Di mata mereka pakaian syurban, hijab, memakai jenggot adalah representase teroris yang harus mereka selalu awasi dan batasi ruang geraknya.

Memang secara factual tidak bisa dipungkiri, yang melakukan aksi teror bom di berbagai tempat adalah orang Islam, namun demikian atas tindakan mereka tidak bisa digeneralisir sebagai tindakan yang mendapat legitimasi pembenaran dari Islam, karena Islam pun mengutuk dan tidak membenarkan tindakan tersebut. Karena opini ini sudah terlanjut menjadi sebuah stigma bagi

${ }^{23}$ Adi Sasono (et.,al.) Solusi Islam atas Problematika Umat (Ekonomi, Pendidikan, dan Dakwah), h. 208-209 
bangsa Amerika, maka kenyataan yang harus diterima oleh umat Islam, kemanapun mereka pergi selalu menjadi bahan perhatian dan kecurigaan.

Oleh karena itu, untuk membendung sejumlah tudingan dan serangan yang mereka tujukan kepada Islam diperlukan suatu formulasi gerakan dakwah yang berimensi ke-rahmatan lil alamin. Yaitu sebuah gerakan dakwah yang menjunjung tinggi dan mengedepankan nilai-nilai kemanusiaan, toleransi, nilai ta'aru, ta'awun, dan ukhuwah. Semua hal ini, akan terwujud apabila melalui tahapan-tahapan strategis yaitu, tahapan ideologis (tahapan dasar/penanaman pondasi aqidah), tahapan konsepsional (tahapan membangun sistem dalam struktur masyarakat), tahapan opresional (mengaktualisasikan semua tahapan menjadi satu kesatuan yang utuh dalam kerangka kehidupan masyarakat). 


\section{Daftar Pustaka}

Achmad, Amrullah. "Dakwah Islam dan Perubahan Sosial Suatu Kerangka Pendekatan dan Permasalahan. Dalam Seminar Nasional dan Diskusi PLP2M. Cet. I; Yogyakarta: Prima Duta, 1983.

Boyle, Prancis. Special Introduction, The Criminality of Nuclear Deterence. Atlanta: Clarity Press, 2002.

Devi Muharrom Sholahuddin, Islam di Mata Barat; Hegemoni Barat Terhadap Perabadan Islam, dalam http://figurdarussalam.blogspot.com./2012/06/Islam-di-mata-barat-hegemonibarat.html.

Hafidhuddin, Didin. Dakwah Aktual. Cet. I; Jakarta: Gema Insani Press, 1998

Hafiduddin, Didin. "Manajemen Dakwah", dalam Adi Sasono (et.,al.) Solusi Islam atas Problematika Umat (Ekonomi, Pendidikan, dan Dakwah). Cet. I; Jajarta: Gema Insani Press, 1998.

Hidayat, Adian Husaini dan Nuim. Islam Liberal, Sejarah Konsepsi, Penyimpangan dan JAwabannya. Cet. I; Jakarta: Gema Insani Press, 2002.

Hitti, Philip K. Islam and The West; Kultural Survey. Princeton, N.J: D. Van Nostrand Co., Inc., 1962.

http://adjis.wordpress.com/2012/12/02/konspirasi-global-menghancurkan-islamdi-indonesia/.

http://ismailkarim86.wordpress.com/2009/08/19/propaganda-asing-di-balik-isuterorisme/.

http://m.republika.co.id/berita/dunia-Islam/Islam-nusantara/14/12/04ng11ng-diprancis-tidak-punya-kumis-dan-berhijab-dicurigai.

http://m.republika.co.id/berita/internasional/global/14/12/03/nfzse1-di-australiamasjid-dituding-sebagai-sarang-teroris.

http://manhajkita.blogspot.com/2012/10/upaya-as-meredam-bangkitnya-islamdi.html.

http://satuumat.blogspot.com/2010/07/gerakan-anti-Islam-antarabangsa.html https://adjhis.wordpress.com.2012/12/02/konspirasi-global-menghancurkanislam-di-indonesia/.

Jamilah, Maryam, Islam dan Orientalisme; Sebuah Kajian Analitik. Cet. II; Jakarta: PT. RajaGrafindo Persada, 1997. 
Musaffar, Chandra. Muslim Dialog dan Teror. Cet. I; Jakarta: PT. Ekuator Publika, 2004.

Rahmat, Jalauddin. Rekayasa Sosial; Reformasi, Revolusi, atau Manusia Besar?.Cet. II; Bandung: PT. Remaja Rosada Kasya, 2000.

Sasono Adi. (et.,al.) Solusi Islam atas Problematika Umat (Ekonomi, Pendidikan, dan Dakwah.

Wahid. Abdul, dan Kawan-kawan, Kejahatan Terorisme Perspektif Agama, HAM, dan Hukum, Bandung; Refika Aditama, 2004.

Wajiran, (Dosen Universitas Ahmad Dahlan Yogyakarta) dalam http://sosbud.kompasiana.com/2012/10/08/upaya-barat-runtuhkanIslam-500089.html.

Wajiran,http://www.uad.ac.id/en/infiltrasi-ideologi-barat-meruntuhkan-islam Zainuddin, dalam jurnal Dakwah UIN Sunan Kali Jaga, Dakwah Rahmatan Lil Alamin, Kajian tentang Toleransi Beragama dalam Surat al-Kafirun, Vol. X, No. 1 Januari 2009. 